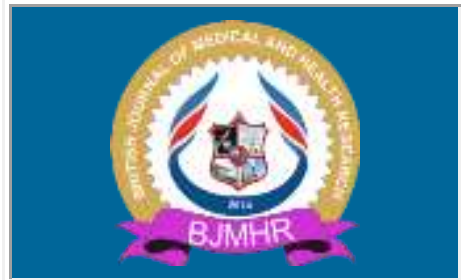

\title{
BJMHR
}

British Journal of Medical and Health Research

Journal home page: www.bjmhr.com

\section{Anticardiolipin Antibodies as Diagnostic Tool for Recurrent Spontaneous Abortion in Saudi Women}

\author{
Syed Tabrez Ali*, Osama Shaikhomar \\ Department of Physiology, Faculty of Medicine, Umm-Al-Qura University, Makkah, Saudi \\ Arabia
}

\section{ABSTRACT}

Purpose of the present study is to evaluate the correlation between high level of anticardiolipin antibodies (aCL) and recurrent spontaneous abortions in Saudi women. An association between anticardiolipin antibodies and gestational age of abortion and duration past abortion in Saudi women living in Western region of Saudi Arabia (Makkah) was determined by collecting blood samples from 100 females who had history of spontaneous recurrent abortion as case group and 100 pregnant healthy women as control group ages ranged between 20 and 40 years, with a mean age of $31.4 \pm 12.69$ years. Average rate of anticardiolipin antibodies in the serum of case group compared with the control group in this study indicated significantly low level in case group ( $p<0.05)$. Based on number of previous miscarriages a significantly high rate with an increase in the number of miscarriage (four and more) was also observed. Results based on gestational age in patients of different miscarriages indicated a consistently and significantly high level of serum anticardiolipin antibodies in second and third miscarriages when compared with the first miscarriage at the age of around 10 weeks, being highest at the gestational age of 11-20 weeks. Results based on duration past of different miscarriages indicated a significantly high level at $\leq 4$ years after their first miscarriage. Moreover estimated levels of serum anticardiolipin antibodies were found to be more or less equal at 5-12 and more than 12 years in all the miscarriages. In conclusion, anticardiolipin antibodies based on number of abortions and gestational age of abortions were increased in all patients just in first 5 years past abortion and then began to fall. However further diagnostic studies are recommended since these antibodies are a potential cause of hypercoagulability and may increase the risk of thromboembolic events with a larger sample size, including different age groups and populations.

Keywords: Anticardiolipin antibodies, recurrent spontaneous abortion, Saudi Arabia

*Corresponding Author Email: taboo1906@hotmail.com

Received 05 March 2020, Accepted 22 March 2020

Please cite this article as: Ali ST et al., Anticardiolipin Antibodies as Diagnostic Tool for Recurrent Spontaneous Abortion in Saudi Women. British Journal of Medical and Health Research 2020. 


\section{INTRODUCTION}

Human immune system some times by mistaken targets the body's own cardiolipin substances present in the outermost layer of cell membrane and platelets and initiates the production of cardiolipin antibodies which are auto antibodies by nature. These autoantibodies by some unknown mechanism badly affect the body's ability to regulate the mechanism of blood coagulation (1).

Since the first development of assays for the detection of antibodies specific for cardiolipin (2), anticardiolipin antibodies are identified in normal healthy controls specially elderly, patients with bacterial and viral infections as well as pregnant women specially suffering with antiphospholipid syndrome (APS) $(3,4)$.

Some common complications of APS associated pregnancy includes repeated miscarriages, placental insufficiency, pre-eclampsia, and retarded fetal growth $(5,6)$. In all these case a heterogeneous group of circulating antibodies has been found in the circulating blood against anionic phospholipids with the most important ones being anticardiolipin antibodies (aCL) (7). These antibodies after bindings with phospholipids, inhibits placental anticoagulant protein as well as gonadotropin release, thereby leading to thrombosis $(8,9,10)$. Although it is difficult to explain how these thrombotic events are associated with the placenta, however, it is suggested that anticardiolipin antibodies may be responsible for a local acute inflammatory response mediated by complement activation and neutrophil infiltration eventually leading to fetal loss (4).

Moreover studies on animal model shows spontaneous miscarriages associated with the passive transfer of purified anticardiolipin IgG (11). However with the normalization of the levels of these antibodies reduces the symptoms with an improvement of the survival rate of fetuses during pregnancy (12).

Pregnant women usually suffers with anti phospholipid syndrome (APS) with the rate of about $0.2 \%$ to $2 \%(1,13)$, where as this syndrome comprises about $10 \%$ of the repeated miscarriages pregnancy loss in general population (14). Although high (aCL) levels are associated with repeated miscarriages and prophylactic treatments can improve the outcome of pregnancy $(5$, 15), however prevention and treatment of repeated miscarriages associated with APL are still controversial.

It is established now that APS is characterized by auto antibodies against negatively charged phospholipids in the serum, and clinically by multiple thromboses, thrombocytopenia, and recurrent fetal loss, but the mechanism by which the antibodies cause the clinical picture are not clear and the pathogenesis of this disorder remains poorly understood. For example, it is difficult to predict who will develop (aCL), or why. Although it is clear from the previous 
serological studies that these anticardiolipin antibodies are more likely to develop clinical manifestations, however, our ability to accurately risk-stratify recurrent spontaneous abortion in patients with these antibodies remains limited. More over our literature survey indicates very few studies regarding (aCL) associated pregnancy loss in Saudi population. The current study has been undertaken to evaluate the prevalence of (aCL) among Saudi women with recurrent miscarriage and to determine any association between (aCL) and number of miscarriage and duration past miscarriage.

\section{MATERIALS AND METHOD}

This study was done on female inhabitants of Makkah, Saudi Arabia. All the subjects included in the current study has age ranged between 22 and 40 years, with a mean age of $31.4 \pm 12.69$ years, after getting approval by the ethics committee of the affiliated institution. All the subjects enrolled in this study were provided with a written informed consent prior to the study. Each candidate was required to complete a physical examination by a certified physician to check the health conditions. Candidates with a history of two or more abortions without any history of medical diseases or drug use was included. Abortion was defined as loss of fetus before a gestational age of 20 weeks or weight of fetal below 500 grams. Candidates with the history of acute and chronic infections, digestive diseases, kidney disease, metabolic and nutritional diseases, rheumatic diseases, endocrine disease, circulation system diseases, burns and muscle trauma, hypertension (systolic pressure $\geq 145 \mathrm{mmHg}$ and/or diastolic pressure $\geq 95 \mathrm{mmHg}$ ), heavy smokers (smoking>22 cigarettes/day), massive blood loss, malnutrition (lose weight, poverty, or special dietary habits) and symptoms associated with low body mass index or marked weight loss, surgery undergone within six months, medication taken within two weeks, blood donation or blood transfusion within four months, strenuous exercise or heavy manual labor were excluded. Individuals were further excluded in accordance with one of the following criteria: Positive results for Hepatitis B surface antigen, Hepatitis C antibodies, or HIV antibodies.

Finally 100 Saudi women with history of miscarriages were selected as case group and 100 healthy women without history of miscarriages and had one or more successful pregnancies selected as control group. In the case group history included parity, live birth, number of miscarriages, gestational age at each miscarriage and duration post miscarriage were determined.

For the experimental purposes five milliliters of blood was drawn by vein puncture. After a clotting period of about 30 minutes at room temperature, samples were centrifuged (ALC centrifuge PK130 U.S.A) at 3400 r.p.m. for ten minutes and serum was collected for testing in sterile serum tubes. Level of anticardiolipin antibodies in samples were measured by enzyme 
linked immunoassay test and use of Orgentec kits (ORGENTEC Diagnostika, Mainz Germany) and relation between mean of anticardiolipin antibodies and number of miscarriage $\geq 3$ and more than 4 , gestational age at the time of abortions ( $\leq 10$ week, $11-20$ weeks, $>20$ week) and duration post abortions ( $\leq 4$ year, 5- 12 years, $>12$ years) were determined. Collected data was analyzed by Student $\mathrm{t}$ tests using SPSS program 17.0 (SPSS Institute, Inc.; Chicago, IL, USA) software for statistical analysis. all results were tabulated as mean \pm standard deviation and a $p$ value $<0.05$ was considered as statistically significant.

\section{RESULTS AND DISCUSSION}

Average rate of anticardiolipin antibodies in the serum of case group compared with the control group in this study as shown in figure-1, indicated significantly low level in case group $(\mathrm{p}<0.05)$.

Estimation of serum anticardiolipin antibodies based on number of previous miscarriages in Saudi women as shown in Figure-2, indicated a significantly high rate $(\mathrm{p}<0.005)$ with an increase in the number of miscarriage (four and more).

Based on gestational age in patients of different miscarriages, data for the average distribution of serum anticardiolipin antibodies is presented in Figures $3 \mathrm{~A}, \mathrm{~B} \& \mathrm{C}$, respectively. Figure $3 \mathrm{~A}$, indicated a consistently and significantly high level of serum anticardiolipin antibodies in second and third miscarriages when compared with the first miscarriage at the age of around 10 weeks ( $\mathrm{p}<0.005)$. Based on gestational age of miscarriages, 11-20 weeks (Figure 3B), and more than 20 weeks (Figure 3C), an increased level of serum anticardiolipin antibodies was observed in the second miscarriage, being highest at the gestational age of 11-20 weeks.

Average distribution of anticardiolipin antibodies based on duration past of different miscarriages is shown in Figures 4 A, B \& C. These results indicated a significantly high level at $\leq 4$ years after their first miscarriage as compared to second and third miscarriages, being highest around four years than 5-12 years and more than 12 years (Figure 4 A). Moreover estimated levels of serum anticardiolipin antibodies were found to be more or less equal at 512 and more than 12 years in all the miscarriages (Figures 4B \& C, respectively). 


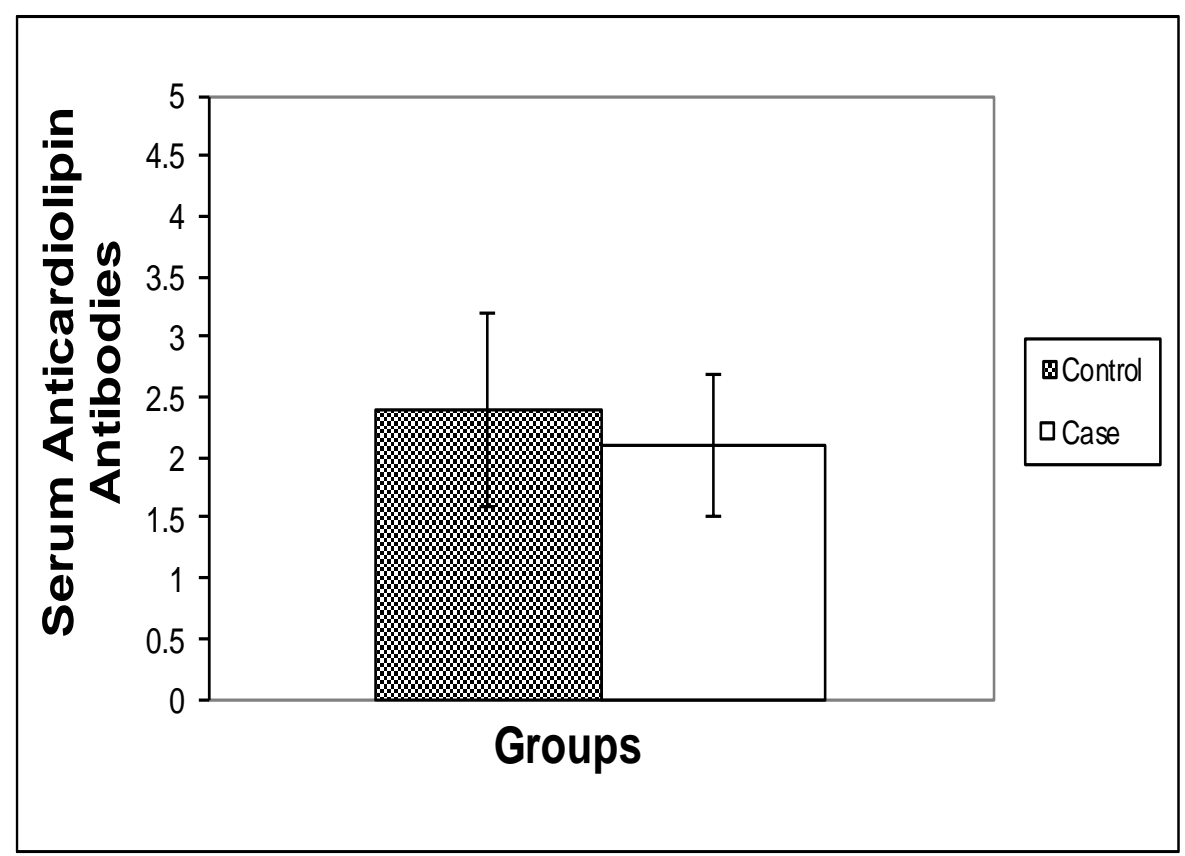

Figure 1: Estimation of serum anticardiolipin antibodies in case group compared with the control group in Saudi women. Values are Mean \pm SD, $(n=100)$. Legend indicates control and case groups.

Note: $\mathbf{n}=$ Total number of subjects examined.

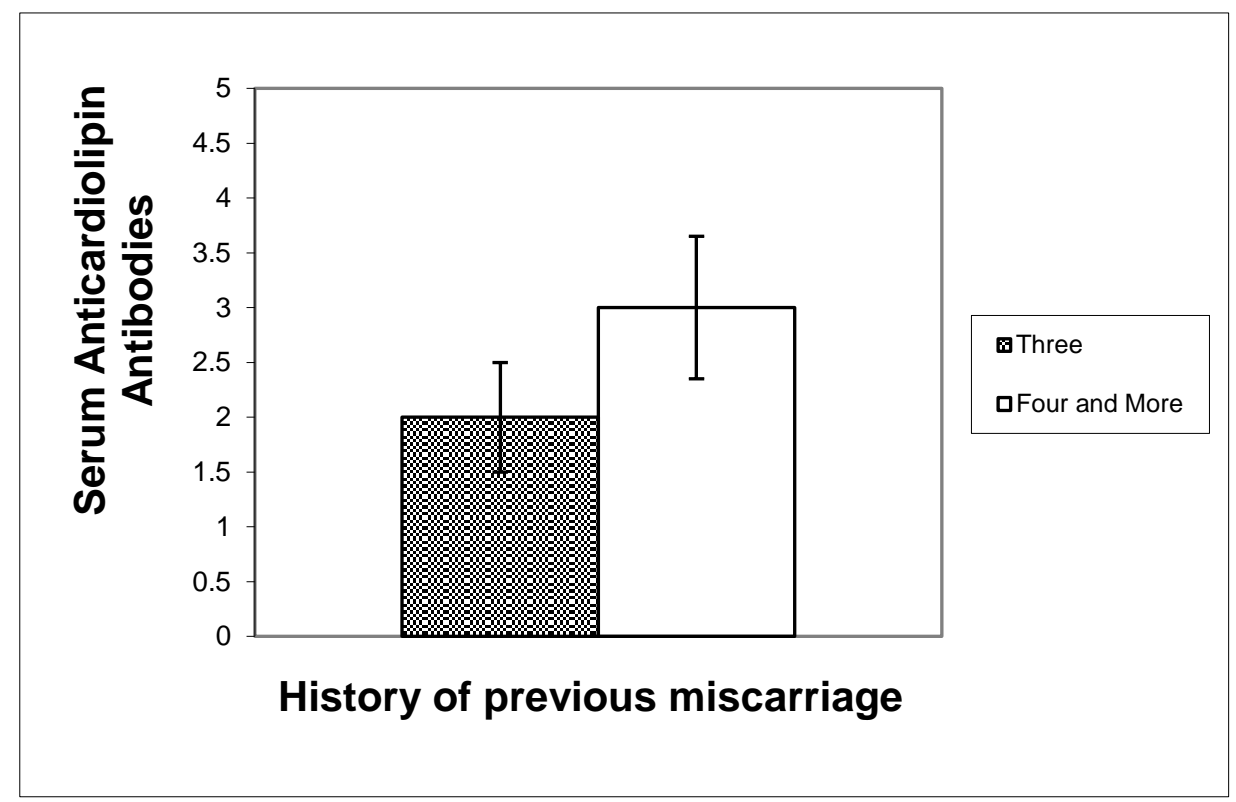

Figure 2: Estimation of serum anticadiolipin antibodies based on number of previous miscarriages in Saudi women. Values are Mean $\pm \mathrm{SD},(n=100)$. Legend indicates number of miscarriages

Note $: \mathrm{n}=$ Total number of subjects examined. $\mathbf{p}<0.005$ 


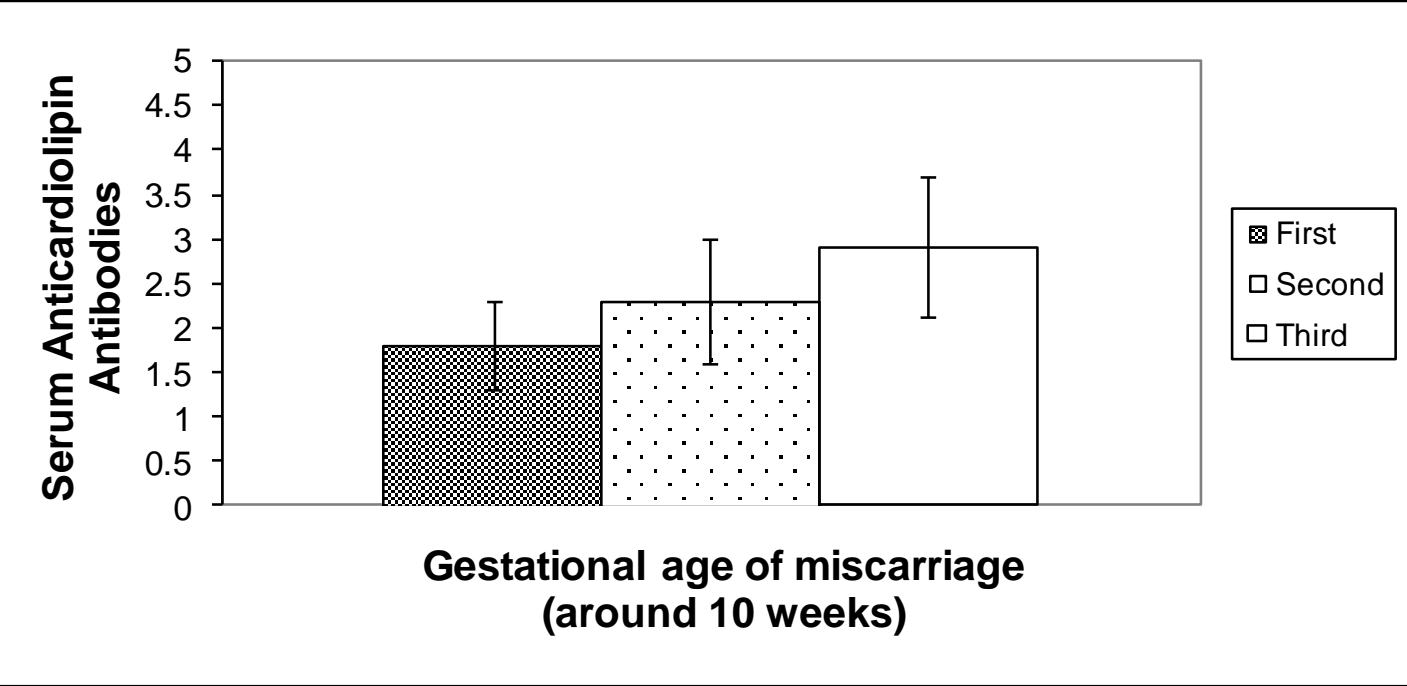

Figure 3-A: Estimation of serum anticadiolipin antibodies based on gestational age of miscarriages ( $\leq 10$ weeks in Saudi women. Values are Mean \pm SD, $(n=100)$. Legend indicates number of miscarriages

Note $: \mathrm{n}=$ Total number of subjects examined. $\mathrm{p}<0.05$

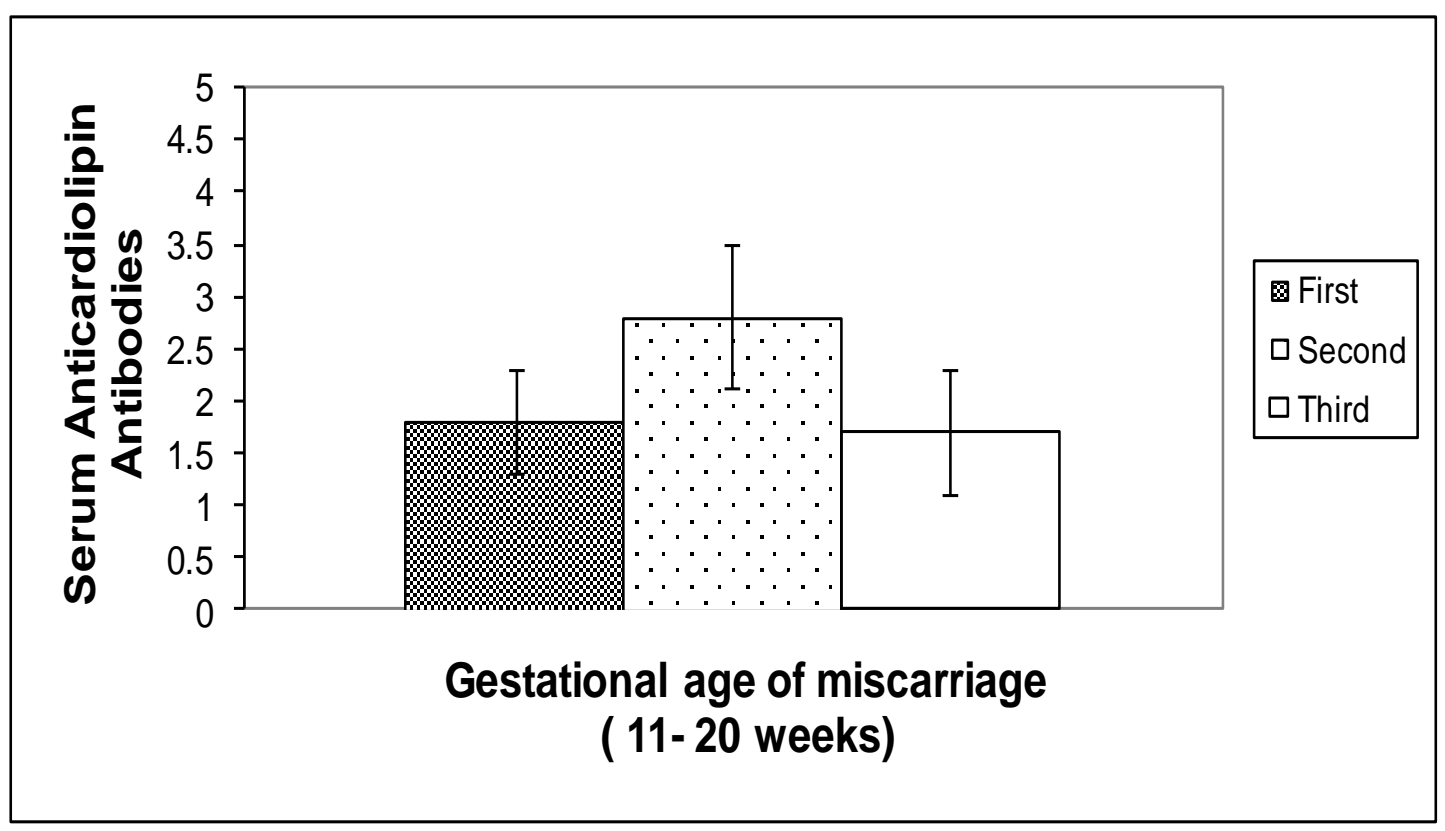

Figure 3-B: Estimation of serum anticadiolipin antibodies based on gestational age of miscarriages (11-20 weeks) in Saudi women. Values are Mean $\pm \mathrm{SD},(\mathbf{n}=100)$.

Legend indicates number of miscarriages

Note $: \mathbf{n}=$ Total number of subjects examined. 


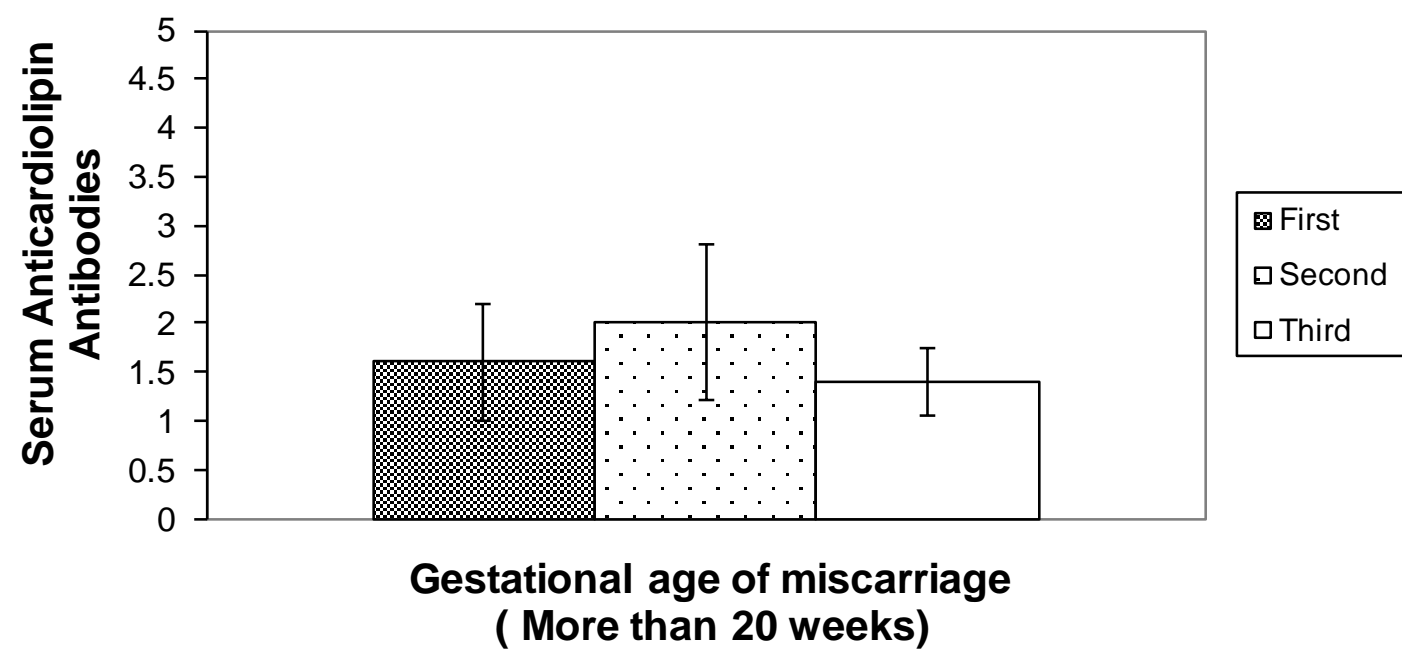

Figure 3-C: Estimation of serum anticadiolipin antibodies based on gestational age of miscarriages (More than 20 weeks) in Saudi women. Values are Mean $\pm \mathbf{S D},(\mathbf{n}=100)$. Legend indicates number of miscarriages

Note: $\mathbf{n}=$ Total number of subjects examined.

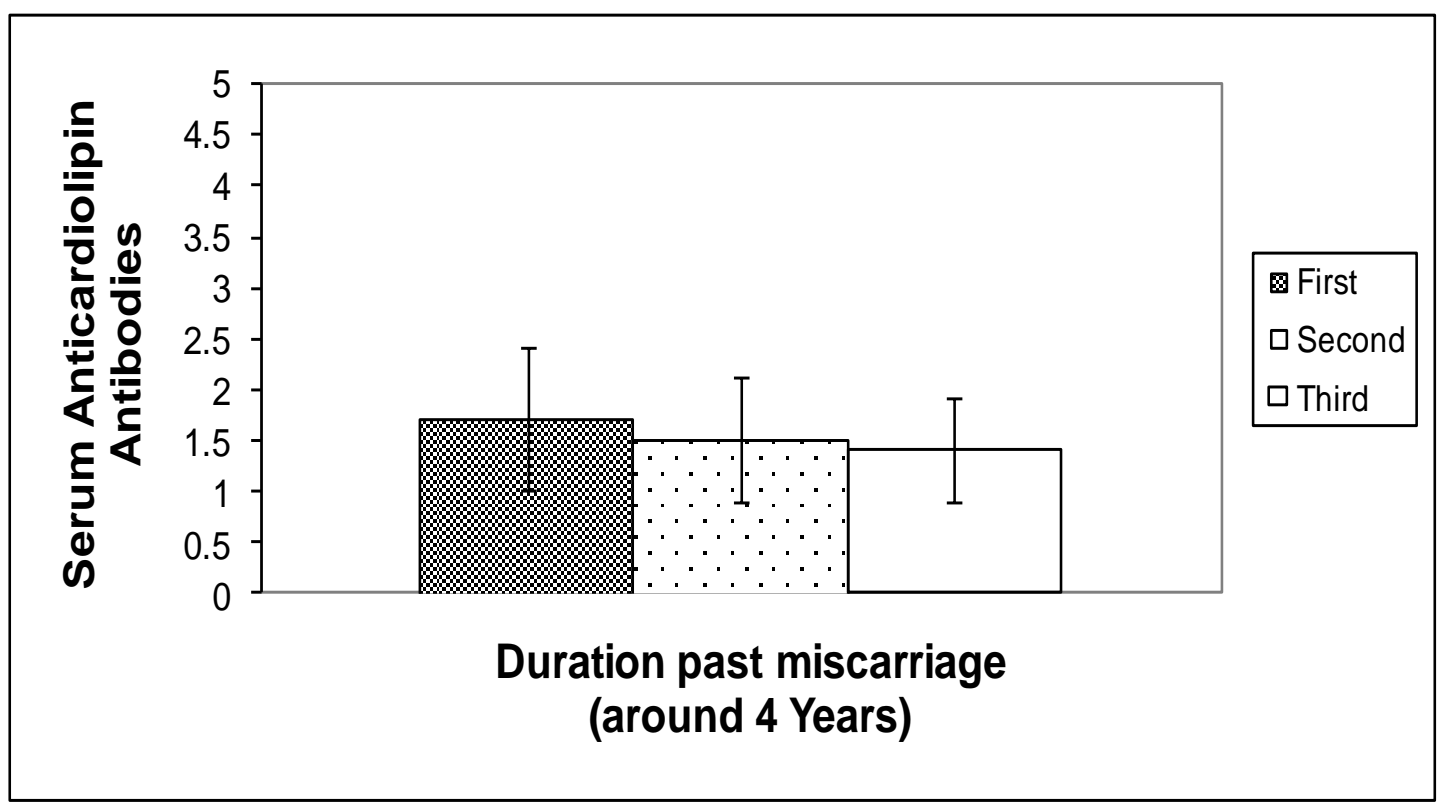

Figure 4-A: Estimation of serum anticadiolipin antibodies based on duration past miscarriages ( $\leq 4$ years) in Saudi women. Values are Mean $\pm S D,(n=100)$. Legend indicates number of miscarriages

Note $: \mathbf{n}=$ Total number of subjects examined. 


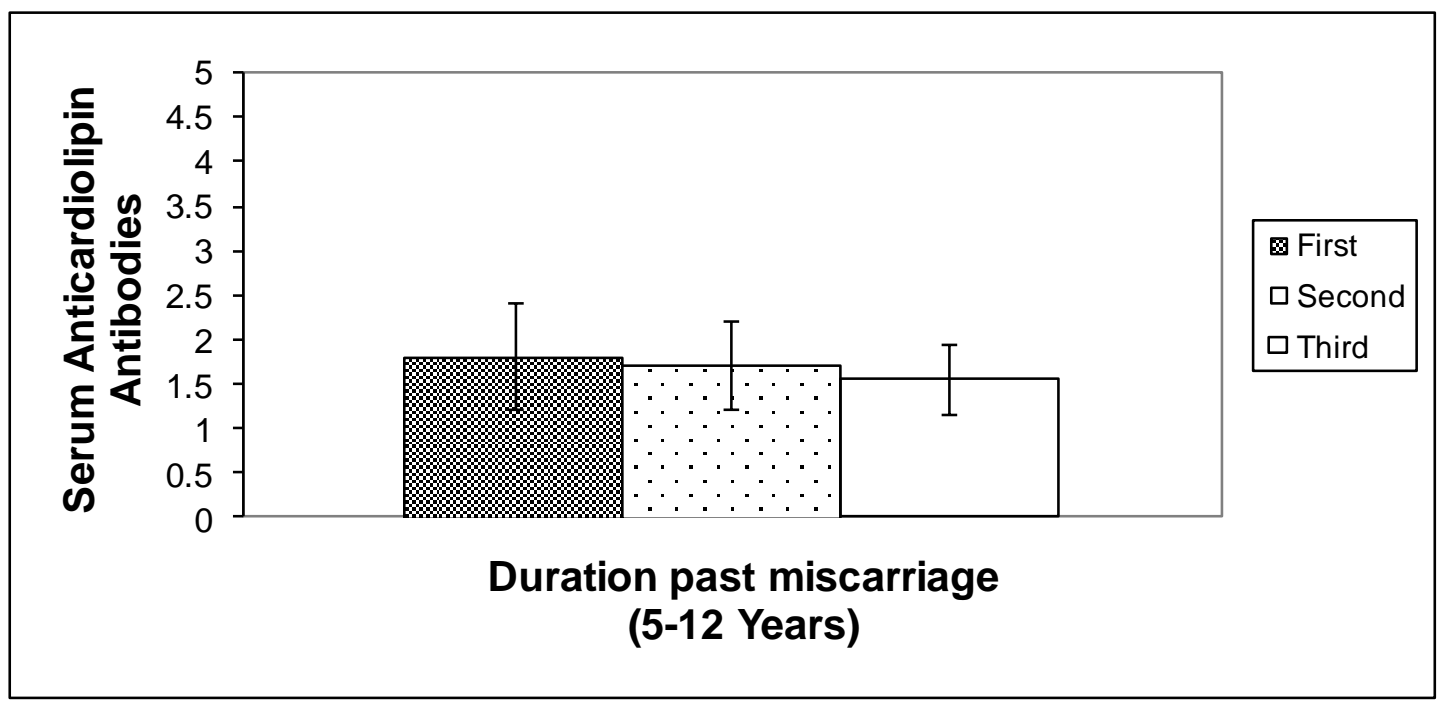

Figure 4-B: Estimation of serum anticadiolipin antibodies based on duration past miscarriages( $\leq 4$ years) in Saudi women. Values are Mean $\pm S D,(n=100)$. Legend indicates number of miscarriages

Note: $\mathbf{n}=$ Total number of subjects examined.

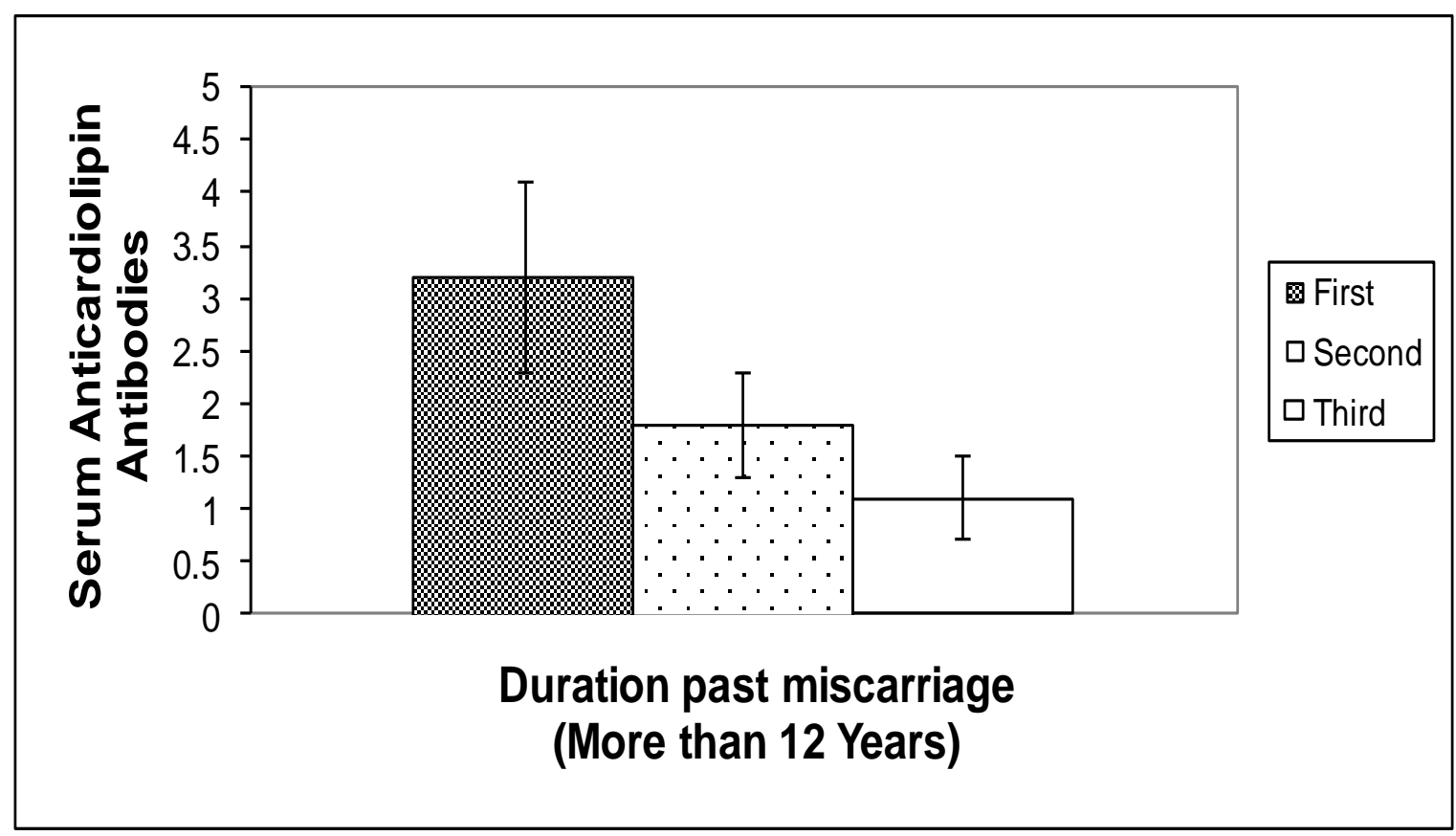

Figure 4-C: Estimation of serum anticadiolipin antibodies based on duration past miscarriages $(\leq 4$ years) in Saudi women. Values are Mean $\pm S D,(n=100)$. Legend indicates number of miscarriages

Note: $\mathbf{n}=$ Total number of subjects examined.

\section{DISCUSSION}

The prevalence and the association of (aCL) have been investigated previously in the patients with unexplained spontaneous losses and those with systemic lupus erythematosus. In a large general obstetric population aCL (IgG or IgM) were found to be correlated only weakly with 
adverse effects (16). In another study (Love etal) (17) evaluated the prevalence of (aCL) and found no association with a history of fetal miscarriage in non- systemic lupus erythematosus (SEL) patients. In a previous study prevalence of aCL was studied in 331 women with a history of at least one spontaneous abortion or fetal death in comparison with 993 controls. (18). Results of this study concluded that there was no justification for considering aCL a risk factor for fetal loss in the absence of a prior adverse obstetric event. Polyclonal and monoclonal aCLs derived from patients of antiphospholipid syndrome have been showed a direct relationship between aCLs and recurrent miscarriage (19). In another study of 108 cases of placental infractions, about $4 \%$ of women showed a positivity of anticardiolipin antibodies (20). However both in vivo animal and in vitro human studies still do not provide a direct relationship between aCLs and spontaneous miscarriage in humans (21). In an other study although both anticardiolipin and antiphosphatidyl serine antibodies were found to be involved for recurrent abortion, however anticardiolipin antibodies were found to be the main cause of recurrent abortion in these women (22).

In our study we found mean anticardiolipin rate in case group was significantly less than control group. These results are in conformity with the findings of Tebo etal (23), who found that overall combined sensitivity of non-recommended antiphospholipid assays was not significantly higher than anticardiolipin tests having no clinical significance at all.

On the other hand in contrast to our results, anticardiolipin was found to be a major cause of recurrent fetal loss (24). Further more, in a general population study women were found to be negative in anticardiolipin antibodies but positive for another antiphospholipid antibodies causing recurrent abortion. Statistical analysis showed $37.1 \%$ involvement of anticardiolipin antibodies for the recurrent abortion, where as in control group this ratio was found to be 5.4 $\%$. (25). One of the most thrombophilic condition is antiphospholipid syndrome is best known as most important cause of recurrent miscarriage (26).

In our results, mean anticardiolipin in case group was lower than control group. More over anticardiolipin antibodies based on number and gestational age of abortions were increased. Whatever the gestational age was higher in all number of abortions, mean anticardiolipin antibodies was always higher. Moreover, almost mean anticardiolipin antibodies in all patients were in high level just in first 5 years post all abortions but decreased after more than 5 years. Differences in dosage, timing of treatment, inclusion criteria and outcome assessment parameters are some of the factors which have resulted in discrepancies in various reports, therefore identification of immunological mechanisms which are involved in pregnancy loss and the action of different therapeutic reagents used for the treatment in these cases is the need of time and well-designed diagnostic studies are needed for further clarification of the relationship between the autoantibodies and recurrent miscarriage. 


\section{FOOT NOTE}

This research is a part of on going research project No: 43509020, Institute of Scientific Research, Umm-Al- Qura University, Makkah, Saudi Arabia.

\section{REFERENCES}

1. Oilveira LH, Hubble CL, Jara LJ, Saway S, Martínez-Osuna P, Seleznick MJ, Angel J, O'Brien W, Espinoza LR. Prevention of anticardiolipin antibody related pregnancy losses with prednisone and aspirin. Am. J Med. 1992; 93(4):403-11.

2. Loizou S, Mccrea JD, Rudge AC, Reynolds R, Boyle CC, Harris EN. Measurement of anticardiolipin antibodies by an enzyme linked immunosorbent assay (ELISA): Standardization and quantification of results. Clin. Exp. Immunol. 1985; 62: 738-745.

3. Hughes GR. Thrombosis, abortion, cerebral disease and the lupus anticoagulant. BMJ. 1983; 287: 1088-1089.

4. Perdan-Pirkmajer K, Thallinger GG, Snoj N, Cucnik S, Zigon P, Kveder T, Logar D, Praprotnik S, Tomsic M, Sodin-Semrl S, et al. Autoimmune response following influenza vaccination in patients with autoimmune inflammatory rheumatic disease. Lupus. 2012; 21: 175-183.

5. Xu j, Chen D, Duan X, Li L, Tang Y, Peng B. The association between antiphospholipid antibodies and late fetal loss: A systematic review and meta-analysis. Acta Obstet. Gynecol. Scand. 2019; 98 (12): 1523-1533.

6. Wendell AW, Ghavari AE, Koike $\mathrm{T}$, et al. International consensus statement on preliminary classification for definitive antiphospholipid syndrome. Arthritis Rheum. 1999; 42:1309-11.

7. de Godoy JM, de Godoy MF, Braile DM, Torres CA. Prevalence of anticardiolipin antibodies in peripheral arterial thrombosis. Angiology. 2000; 51(6):473-477.

8. Samaritan LR, Gharavi AE, Soberano C, Levy RA, Lockshin MD. Phospholipid binding of antiphospholipid antibodies and placental anticoagulant protein. J. Clin. Immunol. 1992; 12:27-35.

9. Di Simone N, Meroni PL, de Papa N, et al. Antiphospholipid antibodies affect trophoblast gonadotropin secretion and invasiveness by binding directly and through adhered beta2-glycoprotein I. Arthritis Rheum. 2000; 43(1):140-50.

10. C Bu, C Zhang, Z Li, Gao L, Xie Z, Cai G. Autoantibodies to plasminogen and tissue plasminogen activator in women with recurrent pregnancy loss. Clin. Exp. Immunol. 2007; 149(1):31-9. 
11. Bakimer R, Fishman P, Blank M, , Sredni B, Djaldetti M, Shoenfeld Y. Induction of primary antiphospholipid syndrome in mice by immunization with a human monoclonal anticardiolipin antibody. J. Clin. Invest. 1992; 89: 15558-63.

12. Salazar-Paramo M, Jara LJ, Ramos A, Barile L, Machado G, García-De La, Torre I. Longitudinal study of antinuclear and anticardiolipin antibodies in pregnant women with systemic lupus erythematosus and antiphospholipid syndrome. Rheumatol. Int. 2002; 22(4):142-147.

13. Semin P. Catastrophic antiphospholipid syndrome and pregnancy. Seminars in perinatology. 2018; 42(1): 26-32.

14. Radu A, Dudu SC, Ciobanu A, Peltecu G, Iancu G, Botezatu R, Gica N, Panaitescu AM. Pregnancy Management in Women with Antiphospholidic Syndrome. Maedica (Buchar). 2019; 14 (2): 148-160.

15. Vials JM. A literature review on the antiphospholipid syndrome and the effect on childbearing. Midwifery. 2001; 17(2):142-149.

16. Lockwood CJ, Romero R, Feinberg RF, Clyne LP, Coster B, Hobbins JC. The prevalence and biologic significance of lupus anticoagulant and anticardiolipin antibodies in a general obstetric population. Am. J. Obstet. Gynecol. 1989; 161: 369373.

17. Love PE, Santoro SA. Antiphospholipid antibodies: anticardiolipin and lupus anticoagulant in systemic lupus erythematosus (SLE) and in non-SLE disorders; prevalence and clinical. Ann. Intern. Med. 1990; 112:682-698.

18. Infante-Rivard C, David M, Gauthier R, Rivard GE. Lupus anticoagulants, anticardiolipin antibodies, and fetal loss. A case-control study. N. Eng.l J Med. 1991; 325: 1063-1066.

19. De Wolf F, Carreras LO, Moerman P, Vermylen J, Van Assche A, Renaer M. Decidual vasculopathy and extensive placental infarction in a patient with repeated thromboembolic accidents, recurrent fetal loss, and a lupus anticoagulant. Am. J Obstet. Gynecol. 1982; 142: 29-34.

20. Franco C, Walker M, Robertson J, Fitzgerald B, Keating S, McLeod A, Kingdom JC. Placental infarction and thrombophilia. Obstet. Gynecol. 2011; 117: 929-934.

21. Urbanus RT, De Groot PG. Antiphospholipid antibodies-we're not quite there yet. Blood Rev. 2011; 25: 97-106.

22. Velayuthaprabhu S, Archunan G. Evaluation of anticardiolipin antibodies and antiphosphatidylserine antibodies in women with recurrent abortion. Indian J Med. Sci. 2005; 59(8): 347-52. 
23. Tebo AE, Jaskowski TD, Hill HR, Branch DW. Clinical relevance of multiple antibody specificity testing in anti-phospholipid syndrome and recurrent pregnancy loss. Clin. Exp. Immunol. 2008; 154(3): 332-8.

24. Sheth JJ, Sheth FJ. Study of anticardiolipin antibodies in repeated abortions - an institutional experience. Indian J. Pathol. Microbiol. 2001; 44(2):117-21.

25. Giasuddin AS, Mazhar I, Haq AM. Prevalence of anticardiolipin antibody in Bangladeshi patients with recurrent pregnancy loss. Bangladesh Med Res Counc Bull. 2010; 36 (1): 10-13.

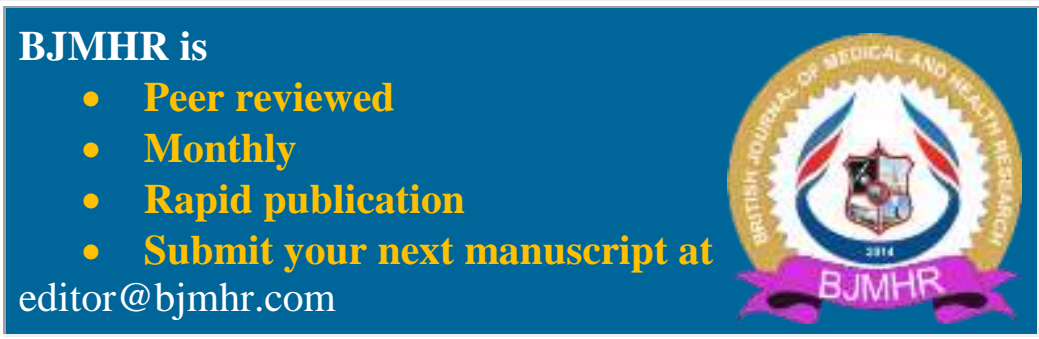

